\title{
Mate choice promotes inbreeding avoidance in the two-spotted spider mite
}

\author{
N. S. H. Tien • G. Massourakis • M. W. Sabelis • M. Egas
}

Received: 11 July 2010/Accepted: 1 February 2011/Published online: 13 March 2011

(C) The Author(s) 2011. This article is published with open access at Springerlink.com

\begin{abstract}
Since inbreeding in Tetranychus urticae can reduce offspring fitness, sexual selection may favour disassortative mate choice with respect to relatedness of the mating partners. We tested whether T. urticae shows this preference for mating with unrelated partners. We chose an experimental set-up with high potential for female choosiness, since females only mate once and are therefore expected to be the choosier gender. An adult virgin female was placed together with two adult males from the same population. One male was unrelated and the other male was related-a brother with whom she had grown up. Significantly more copulations $(64 \%)$ took place with the unrelated male. Time to mating did not depend on the female-to-male relatedness. The remaining (non-copulating) male tried to interfere with the ongoing mating in the majority of cases, but this interference did not depend on the female-to-male relatedness. These results imply that T. urticae (a) can recognize kin (via genetic and/or environmental similarity) and (b) has the potential to avoid inbreeding through mate choice.
\end{abstract}

Keywords Tetranychus urticae $\cdot$ Inbreeding depression · Disassortative mating

\section{Introduction}

Mating with relatives-inbreeding - is detrimental to fitness for the two-spotted spider mite, Tetranychus urticae. Inbred offspring mature slower than outbred offspring (Tien 2010) and inbred adult females have lower reproductive output (Perrot-Minnot et al. 2004; Tien 2010). This negative impact is expected to drive sexual selection for mating preference with unrelated partners (cf Metzger et al. 2010). Here, we ask whether T. urticae can differentiate between kin and non-kin partners in mate choice, as a mechanism to avoid

N. S. H. Tien · G. Massourakis · M. W. Sabelis · M. Egas ( ()

Institute for Biodiversity and Ecosystem Dynamics, University of Amsterdam,

P.O. Box 94240, 1090 GE Amsterdam, The Netherlands

e-mail: C.J.M.Egas@uva.nl

N. S. H. Tien

e-mail: N.S.H.Tien@uva.nl 
inbreeding. This mite species is shown to exhibit mate choice (with regard to bacterial infection status) as a means to increase fitness (Vala et al. 2004), but the question remains whether it can also distinguish between relatives and non-relatives and whether it can select a mate so as to avoid inbreeding.

For females of $T$. urticae usually only the first mating results in fertilization (Helle 1967), whereas males can mate multiple times (Krainacker and Carey 1989, 1990). Consequently, females are expected to be the more choosy sex. Females are often mated directly after (or even during) emergence from the pre-adult quiescent phase (ecdysis) (Potter et al. 1976b). Usually these females are mated by the male that guarded her during the moulting phase (Potter et al. 1976a, b), which likely provides her with little opportunity to choose between mates. If a female does not mate directly after ecdysis (something we regularly observe in our lab populations), she can mate at a later stage, in which case the female probably has more opportunity to reject or accept males. In order to examine whether mate choice can depend on relatedness in T. urticae we used active adult females, to maximize the potential for female choosiness. Such a female was placed with an unrelated male and a related male, where the latter male was a brother with whom she had grown up together (and with whom she thus shared both a genetic and environmental background), and mating behaviour was recorded in order to test our hypothesis of a mating preference for unrelated partners.

\section{Materials and methods}

\section{Spider mite population}

In September 2009 a sample of more than 500 spider mites was collected along a 5 meter transect of spindle bushes (Euonymus europaeus) in the dunes at the Dutch coast near the town of Castricum. This population was maintained (minimal population size $=500$ ) in the laboratory under climate-controlled conditions $\left(23^{\circ} \mathrm{C}, 60 \%\right.$ humidity, $\left.\mathrm{L}: \mathrm{D}=16: 8\right)$ on bean leaves (Phaseolus vulgaris), which were placed on wet cotton wool surrounded by water in an open plastic container. The individuals used in the mate choice experiment were subjected to the same climate-controlled conditions as above, unless stated otherwise.

\section{Mate choice}

The experiment started after the population had been kept in the laboratory for 2 months (c. eight generations). Age cohorts of related offspring were created by isolating the broods of individual females. Adult mated females were taken from the mite culture and placed individually on leaf discs (with a diameter of $1.5 \mathrm{~cm}$ ) cut from bean leaves and placed on wet cotton wool in four small plastic containers (ten leaf discs per container). After $48 \mathrm{~h}$ the females were removed and the offspring were allowed to develop. After 10 days, one to three sisters in the pre-adult moulting stage (i.e., the oldest sisters present on the leaf disc) were taken from each leaf disc and placed together on a fresh leaf disc for 3 days. The containers with the old leaf discs (with all males and the remaining females) were placed at lower temperatures $\left(20^{\circ} \mathrm{C}\right)$ for these 3 days in order to slow down the mite's development: the males and females thus reach adulthood later and the males are motivated to stay on the leaf disc since there are unmated females around. In absence of females to be mated, males tend to disperse and in the process they are likely to die in the wet cotton wool surrounding the leaf disc (pers. obs. NSH Tien). 
The mate choice experiments took place at $23^{\circ} \mathrm{C}$ in the laboratory. Mating was tested between 10 am and $3 \mathrm{pm}$. This was done because preliminary work showed that the time to first mating increased in the course of the day, suggesting a decrease in willingness to mate. Fresh leaf discs were placed individually on wet cotton wool in small Petri-dishes. A female was placed on the leaf disc and left to acclimate for c. $10 \mathrm{~min}$. After this period a brother and an unrelated male were added to the leaf disc. The brother was picked from the leaf disc the female inhabited up to 3 days earlier. The unrelated male was picked randomly from a leaf disc from another container. The experiment was randomized, i.e. the same families could be tested for both "roles" (brother versus unrelated male). If no mating took place within 10 min the sample was discarded and another random combination of families was used.

Males were distinguished from each other by small individual phenotypic differences, and in most of the trials through continuous visual observation of all three individuals. Phenotypic differences were mostly differences in the colour of the intestinal tract or in tarsus width. Care was taken to vary these differences between trials. Mating can be described as follows: the male arches his abdomen up to the tip of that of the female. This is accompanied by the male clutching to the female with his legs (from underneath), which enable them to continue mating even when the female starts to move around. If such a position was kept for at least $30 \mathrm{~s}$, the action was scored as a mating. Mate choice (related or unrelated) and time to mating were recorded. We also recorded whether the other (noncopulating) male tried to interrupt the ongoing copulation. Interference was defined as the male arching up his abdomen and trying to pry his abdomen between those of the copulating male and female. In one trial the presence/absence of interference was not recorded.

The experiment was replicated three times, with a sample size of 16, 34 and 14 successful matings for the three replicates respectively. The mate choice data were analyzed with replicated $G$-tests (Sokal and Rohlf 1995, p. 715). Time to mating was analyzed in an ANOVA, with mate choice (related versus unrelated) and replicate as explanatory factors. Time was expressed in seconds and was first square-root transformed before use in the ANOVA. The chance that a male tried to interrupt the mating was analyzed with a $2 \times 2$ contingency table and a $G$-test for independence. The table had the criteria "relatedness" (related versus unrelated) and "interruption" (yes vs. no) (Sokal and Rohlf 1995, p. 729). The $G$-test determined whether the frequency of interruption was dependent on relatedness.

\section{Results}

For $74 \%$ of the females tested (64 out of 87), mating took place within the first $10 \mathrm{~min}$ and $64 \%$ (41 out of 64) of these matings took place between the unrelated male and female (Table 1). No significant heterogeneity was found between the data from the three replicate experiments and in all replicates more than $50 \%$ of the mating took place between the unrelated individuals (Table 1). For the pooled data, the percentage mating between unrelated individuals was significantly more than $50 \%$ (Table 1; Fig. 1). One of the three replicates also yielded a significant preference for mating between unrelated partners [i.e. the replicate with the most samples: replicate 2 (Table 1)].

Time until mating was not significantly influenced by either partner choice $\left(F_{1,60}=\right.$ $0.01, P=0.9)$ or replicate $\left(F_{2,60}=1.6, P=0.2\right)$. The average $( \pm \mathrm{SE})$ time until mating with an unrelated male was $246 \pm 34 \mathrm{~s}$ ) and the time to mating with a brother was $232 \pm 20 \mathrm{~s}$. The brother tried to disrupt the mating in $76 \%$ of the cases (31 out of 41 ), 
Table 1 Frequency data and statistical analyses of the mate choice experiments

\begin{tabular}{|c|c|c|c|c|c|c|c|c|c|c|}
\hline \multirow[t]{2}{*}{ Replicate } & \multicolumn{2}{|l|}{ Choice } & \multirow[t]{2}{*}{ No choice } & \multicolumn{3}{|c|}{ Individual $G$-tests } & \multicolumn{4}{|c|}{ Replicated $G$-test } \\
\hline & Unrelated & Related & & $G$ & $d f$ & $P$ & & $G$ & $d f$ & $P$ \\
\hline 1 & 9 & 7 & 11 & 0.25 & 1 & 0.62 & Heterogeneity & 1.35 & 1 & 0.5 \\
\hline 2 & 24 & 10 & 7 & 5.94 & 1 & 0.01 & Pooled & 5.13 & 1 & 0.02 \\
\hline 3 & 8 & 6 & 5 & 0.29 & 1 & 0.59 & & & & \\
\hline
\end{tabular}

"Choice" Number of samples per replicate where mating took place between unrelated or related partners. "No choice" Number of samples where no mating took place within $10 \mathrm{~min}$. "Individual $G$-test" $G$-tests per replicate. "Replicated $G$-test" $G$-test for independence over all three replicates, where "heterogeneity" refers to the heterogeneity of the replicates $(P>0.05$ indicates the frequency distributions of the replicates are not significantly different from each other) and "pooled" refers to the analysis of the overall mate choice frequencies (where $P<0.05$ indicates the choice for unrelated and related partner differs from a 50\%:50\% distribution)

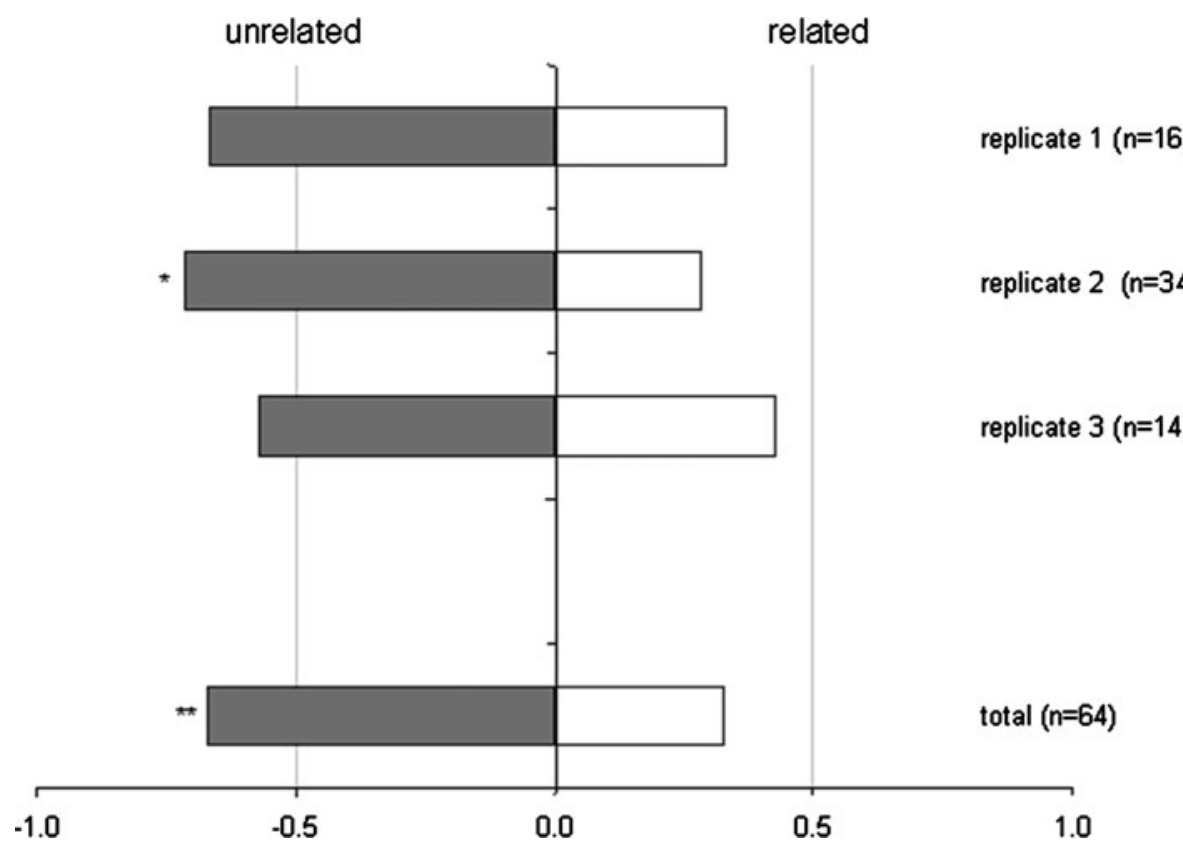

Fig. 1 Mate choice experiment: fraction of matings with a familiar or unfamiliar partner. A virgin female was placed with two adult males on a leaf disc, one of which was related and one was unrelated. The experiment was replicated three times [in parentheses are the sample sizes $(n)$ ]. $* P<0.05$ and $* * P=0.01$

while the unrelated male tried to interrupt in $65 \%$ of the cases (15 out of 22). These frequencies were not significantly different from each other $\left(G_{1}=0.40, P=0.5\right)$.

\section{Discussion}

In our experimental set-up an adult virgin female was placed together with a related and an unrelated adult male, in order to investigate whether $T$. urticae avoids inbreeding through 
disassortative mate choice. The related and unrelated male in this experiment differed in more than only genetic similarity: related individuals were also individuals that grew up in the same territory, whereas unrelated individuals were individuals that grew up in different territories. These combined differences in genetic and environmental backgrounds were chosen because recognition of kin can take place either through recognition of genetic relatedness or through the detection of cues from a shared environment (Pusey and Wolf 1996), and the mechanism for T. urticae is unknown (but see Schausberger (2007) for an analysis of the mechanism for phytoseiid mites). Females usually cluster their eggs within a small webbed area and the juveniles tend not to disperse from their natal site (Helle and Sabelis 1985). A shared habitat during juvenile development is therefore likely correlated to genetic relatedness and could make an efficient proxy for recognition of relatedness. Thus, recognition of environmental cues may play a significant role in this species. Since no information is available on the mechanism of kin recognition in T. urticae, we chose to vary both. In this situation, in the majority of cases (almost 2/3) mating occurred between the female and the unrelated male. This yields a proof of principle: Tetranychus urticae individuals can distinguish between related and unrelated conspecifics and can show preference for an unrelated partner. Since mating with unrelated partners may promote offspring fitness (Perrot-Minnot et al. 2004; Tien 2010), this disassortative mate choice is possibly adaptive.

The time taken until copulation did not differ between the ultimate mate choices. Also, once mating was initiated, the probability of interference by the remaining male did not differ with the relatedness of this male and the female, even though males tried to interfere with the ongoing mating in a considerable proportion of all cases (i.e. 73\%). In none of the cases of attempted interference did this seem to effectively break up a mating, because mating did not stop once interference started (pers. obs. Tien). Yet, the influence may have been more subtle and may have decreased the time or efficiency of the mating. We did not, however, collect data to examine the behaviour of the three adults in such detail. Thus, the tentative conclusion would be that males seem equally vigorous in their interference, whether they are related to the female or not.

In order to provide the females a high potential for participation in the mate choice decisions, we used adult and well fed females. Indications that females may prefer mate choice to commence once they are active adults are found in the closely related spider mite Tetranychus kanzawai (Oku 2009). In this species, females in the pre-adult moulting phase that are guarded actively attract other males, probably via pheromones. Since spider mite males often fight over females, this suggests quiescent females try to exert some influence on their future mate. However, T. kanzawai females that are not guarded any more, also stop attracting males (i.e., more than unguarded females do. (Oku 2009), Table 1b). We therefore suggest that quiescent females prefer not to be guarded at all and prefer to become adult before the process of mate choice starts. The same preference for later mating may be expected for females of T. urticae.

In our experimental set-up, each of the three adults may have played a role in the ultimate mate choice. The female was often seen walking away when being approached by a male (pers obs Tien), which would be a method for females to reject a mate. Although males can mate multiple times (Krainacker and Carey 1989, 1990) — and are thus probably less choosy than females-fitness costs for males may be present. Males sometimes fight over females, during which they can injure their opponent (Potter et al. 1976a, b). If males are confronted with other males, they will have to decide whether and how hard to fight for a particular female, which may make males choosy too. In our experimental set-up, however, little fighting was seen before copulation commenced (pers. obs. Tien). It would be interesting to test mate choice in situations with more male competition, for example, in a set-up with 
more males present. Also, the females in this experiment had been adult for c. 2 days, which is an age at which females are usually already mated. Perhaps the males would be more 'perceptive' of younger adult females, which may lead to more competition between males. In addition, since males often guard quiescent females it would be interesting to investigate the relationship between relatedness and male willingness to guard. Another important hiatus in our knowledge on partner choice in $T$. urticae concerns the relative natural occurrence of mating preceded by guarding or not. Research on this subject (Potter et al. 1976b) has been undertaken under artificial conditions in the laboratory (involving high crowding on a small leaf disc) and likely does not reflect the relative frequency of guarding in the wide variety of field conditions. More work on this subject is needed, in order to better understand the relative influence of males and females in the mate choices of this species. Also, since being choosy can be costly, the extent of female choosiness with regard to mate choice is probably dependent on local demographic conditions such as population density and the operational sex ratio. It would thus also be interesting to investigate the extent of choosiness under a variety of demographic conditions.

In conclusion, $T$. urticae has the ability to use mate choice as a mechanism to avoid inbreeding. Taking into account the high potential for inbreeding in this species, it would be interesting to more clearly understand the adaptive importance of and the precise mechanism underlying this behaviour.

Open Access This article is distributed under the terms of the Creative Commons Attribution Noncommercial License which permits any noncommercial use, distribution, and reproduction in any medium, provided the original author(s) and source are credited.

\section{References}

Helle W (1967) Fertilization in the two-spotted spider mite (Tetranychus urticae: Acari). Entomologia Experimentalis Et Applicata 10:103-110

Helle W, Sabelis MW (1985) Spider mites. Their biology, natural enemies and control. Elsevier, Amsterdam Krainacker DA, Carey JR (1989) Reproductive limits and heterogeneity of male two-spotted spider mites. Entomologia Experimentalis Et Applicata 50:209-214

Krainacker DA, Carey JR (1990) Spatial and temporal dynamics of 2 spotted spider mites, Tetranychus urticae Koch (Acari: Tetranychidae). J Appl Entomol-Zeitschrift Fur Angewandte Entomologie 109:481-489

Metzger M, Bernstein C, Hoffmeister TS, Desouhant E (2010) Does kin recognition and sib-mating avoidance limit the risk of genetic incompatibility in a parasitic wasp? PLoS ONE 5:e13505

Oku K (2009) Female mating strategy during precopulatory mate guarding in spider mites. Anim Behav 77:207-211

Perrot-Minnot MJ, Migeon A, Navajas M (2004) Intergenomic interactions affect female reproduction: evidence from introgression and inbreeding depression in a haplodiploid mite. Heredity 93:551-558

Potter DA, Wrensch DL, Johnston DE (1976a) Aggression and mating success in male spider mites. Science 193:160-161

Potter DA, Wrensch DL, Johnston DE (1976b) Guarding, aggressive behavior, and mating success in male twospotted spider mites. Ann Entomol Soc Am 69:707-711

Pusey A, Wolf M (1996) Inbreeding avoidance in animals. Trends Ecol Evol 11:201-206

Schausberger P (2007) Kin recognition by juvenile predatory mites: prior association or phenotype matching? Behav Ecol Sociobiol 62:119-125

Sokal RR, Rohlf FJ (1995) Biometry: the principles and practice of statistics in biological research, 3rd edn. WH Freeman and Co, New York, NY, USA

Tien NSH (2010) Evolutionary genetics of life-history traits in a haplodiploid mite. PhD Dissertation, University of Amsterdam, Amsterdam, The Netherlands

Vala F, Egas M, Breeuwer JAJ, Sabelis MW (2004) Wolbachia affects oviposition and mating behaviour of its spider mite host. J Evol Biol 17:692-700 